East African Medical Journal Vol. 87. No. 2 February 2010

CONGENITAL AFIBRINOGENAEMIA IN A KENYAN FEMALE CHILD: CASE REPORT

G. W. Kitonyi, MBChB, FRCPath, Senior Lecturer, Haematology and Blood Transfusion Unit, Department of Human Pathology, University of Nairobi, P.O. Box 19676 - 00202, Nairobi, Kenya, A. Duncan, MBChB, FACP, Director, Special Haemostasis Laboratory, Emory University Hospital, Atlanta GA 30322, J. N. Githang'a, Senior Lecturer, College of Health Sciences, J. A. Rajab, MBChB, MMed (Path), MPH, Lecturer, Haematology and Blood Transfusion, Department of Human Pathology, University of Nairobi, College of Health Sciences, E. A. Nyaligu, Dip. Med. Lab. Technology HND (Haem/Biochem), Dip(HRM) Senior Laboratory Technologist, Medipath Laboratories Ltd, Nairobi and J. Ireri, HDMLS, MSc, Chief Medical Technologist, Department of Human Pathology, College of Health Sciences, University of Nairobi, P.O. Box 19676 - 00202, Nairobi, Kenya

Request for reprints to: Dr. G. W. Kitonyi, P.O. Box 21494 - 00505, Nairobi, Kenya

\title{
CONGENITAL AFIBROGENAEMIA IN A KENYAN CHILD: CASE REPORT
}

\author{
G. W. KITONYI, A. DUNCAN, J. N. GITHANG'A, J. A. RAJAB, \\ E. A. NYALIGU and J. IRERI
}

\begin{abstract}
SUMMARY
Congenital afibrinogenaemia (CA), is a rare inherited bleeding disorder characterised by complete deficiency of fibrinogen in the plasma. Blood clotting tests are indefinitely prolonged in patients. The mode of inheritance is autosomal recessive. Typically patients present with excessive cord bleeding after birth with intracerebral haemorrhages reported in childhood. Other manifestations include musculoskeletal haemorrhages, mucocutaneous bleeds with poor wound healing reported occasionally. In females, menorrhagia, repeated early pregnancy loss and post-partum haemorrhages are common. We present a four year old female who initially presented with severe cord bleeding after birth, warranting a blood transfusion. Currently she experiences recurrent epistaxis, easy bruising and excessive post -traumatic haemorrhages. All her clotting times are markedly prolonged. Her plasma fibrinogen and fibrinogen antigen are undetectable. An older sibling died from excessive cord haemorrhage after birth. Bleeds in CA respond very favourably to fibrinogen concentrates, cryoprecipitate and fresh plasma. To date, 242 cases of CA have been reported worldwide, none of them in Kenya. Our aim in reporting this case is to document the disorder, and also to raise the index of suspicion of the condition.
\end{abstract}

\section{INTRODUCTION}

First described in 1920, CA is a rare inherited bleeding disorder characterised by complete defficiency of fibrinogen in the plasma. CA is classified as a rare bleeding disorder with a global prevalence one per one million of population (1). Figure 1 shows the internationally recognised rare inherited bleeding disorders (RBDs), to which CA belongs. According to the international Rare Bleeding Disorders Database (RBDD), only 242 cases of CA had been reported worldwide by November 2009 (2). The mode of inheritance of CA is autosomal recessive. In the neonatal period up to $85 \%$ of patients with CA experience excessive umbilical cord haemorrhage after birth. The disorder may also manifest with musculoskeletal haemorrhages and mucocutaneous bleeds including epistaxis and haemarthrosis. In infancy and childhood, intracrebral haemorrhage is the leading cause of death (3). Untreated, most females experience menorrhagia, early pregnancy loss and post-partum haemorrhages. Poor wound healing has been reported in some patients. Surprisingly thrombosis has been reported occasionally in patients with CA (1). Coagulation blood tests are indefinitely prolonged and fibrinogen, including fibrinogen antigen, is undetectable in the plasma (4). It is important to make a firm diagnosis in these patients because their bleeds respond very favourably to treatment with fresh plasma, cryoprecipitate or fibrinogen concentrates (5). In treated females, fertility is preserved and the quality of life is greatly improved (6).

We present a case of CA in a black African, Kenyan child, not only to document the case, but also to raise awareness of the condition and its clinical behaviour. 
Figure 1

Prevalence of patients affected by RBDs

\begin{tabular}{lccccccccc}
\hline Type of deficiency & Fibrino & FII & FV & FV+FVIII & FVII & FX & FXI & FXIII & TOTAL \\
\hline $\begin{array}{l}\text { Number of } \\
\text { affected patients }\end{array}$ & 242 & 55 & 238 & 496 & 934 & 351 & 776 & 211 & 3303 \\
\hline
\end{tabular}

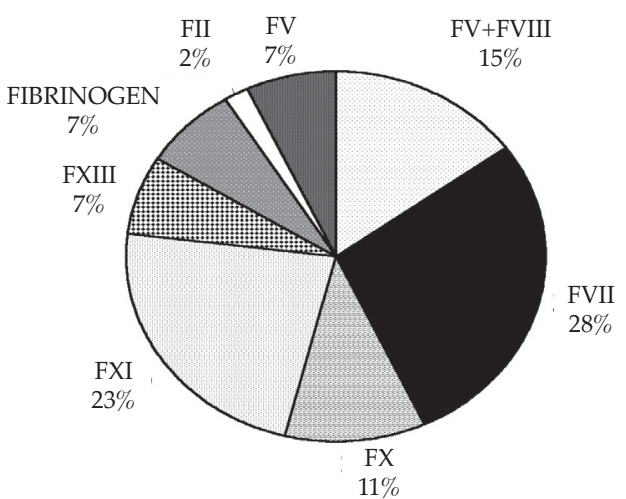

NB: Data from rare bleeding disorders database: www.rbdd.org

$R B D s=$ Rare bleeding disorders

\section{CASE REPORT}

The patient, a four year old black female, was referred for haematology review with a history of recurrent epistaxis and prolonged post traumatichaemorrhage since birth. On enquiry, it transpired that the patient had bled profusely from the umbilicus cord a few hours after birth, necessitating a blood transfusion. Further enquiry revealed that the patient had bled excessively following uveoectomy, (a traditional cultural practice in some Kenyan communities, performed mostly by non- medical personnel, and believed to reduce the frequency of respiratory infections in children), necessitating a second blood transfusion. Prior to haematology referral, the patient had another severe bleed following incision and drainage of an "abscess" on the left leg, which turned out to be a haematoma. This latter bleed however settled and the wound healed well. According to the family history, an older brother of the patient had bled from the umbilical cord a few hours after birth, and died before arrival to the hospital. The parents of the patient are unrelated and they were unaware of any bleeders on either side of the family. At the time of referral, the only significant physical findings the patient had were small haematomata on the upper limbs and the trunk, but otherwise looked healthy.
Laboratory examination included a full blood count and coagulation studies. Table 1 shows results of coagulation work up, indicating grossly prolonged prothrombin time, APTT and thrombin time. A blood sample taken into a plain vacutainer tube, from the patient, and left at room temperature, had not clotted, one week later, when it was disposed off. Bleeding time was normal and a full blood count revealed a haemoglobin level of $10.3 /$ dl with features of iron deficiency. A mild neutrophil leucocytosis and a platelet count of 792 x $10^{9} / \mathrm{L}$. Tests of liver function were all normal. The abnormal clotting times were completely corrected by a 1:1 mixture of patient's plasma with normal plasma. This pattern of results pointed to a fibrinogen disorder. There was no detectable fibrinogen by Clauss method as measured by ST4 Stago coagulometer with Fibrotec Fib kit. A frozen plasma sample sent to the Royal Free Hospital Haemophilia Centre, London, yielded identical results as those obtained in Nairobi, with an indefinitely prolonged reptilase time. In addition fibrinogen antigen was reported below 0.1 gldL, (no detectable fibrinogen antigen). In view of the clinical background and the laboratory findings, the patient was diagnosed with CA. 
Table 1

Coagulation work up

\begin{tabular}{|c|c|c|c|}
\hline Test & Patient's results & & ference range \\
\hline $\begin{array}{l}\text { Bleeding time (Dukes) } \\
\text { minutes) }\end{array}$ & 2 minutes 3 seconds & - & (Normal up to \\
\hline Prothrombin time & $>180$ seconds & - & (control 12.0 seconds) \\
\hline APTT & $>180$ seconds & & (control 36.0 seconds) \\
\hline Thrombin time & $>180$ seconds & - & (control 11.3 seconds) \\
\hline Fibrinogen (Clauss) & Not detectable & - & $(1.8-3.6 \mathrm{~g} / \mathrm{dl})$ \\
\hline Fibrinogen antigen & Not detectable & & \\
\hline
\end{tabular}

Although ideally bleeds in CA should be managed with fibrinogen concentrates, this product is currently unavailable in Kenya and we are therefore managing this patient's sleeds with fresh plasma, cryoprecipitate and antifibrinolytics. The patient is also receiving iron supplements. Counselling regarding possible pregnancies in the future is planned for. It is notable that despite very abnormal coagulation tests, (indefinitely prolonged clotting times), and in spite of the few bleeding episodes, the patient remains remarkably well.

\section{DISCUSSION}

The patient reported here shows typical clinical and laboratory features of CA, a very rare inherited bleeding disorder. A literature search did not reveal other reports of CA in Kenya. This report therefore adds on to the list of documented rare bleeding disorders in the African continent.

The patient's presentation calls to attention the importance of the pattern of haemorrhages in the newborn baby as possible indicators of an inherited congenital bleeding disorder. Excessive cord haemorrhage which was a major feature in the patient, and an older sibling, is a well recognised feature of CA.

In haemophilia and other more common inherited bleeding disorders, the clinical severity of the disorders tends to mirror the degree of prolongation or abnormality of the coagulation tests. Paradoxically and typical of CA, despite indefinitely prolonged coagulation tests, most patients have disproportionately less bleeding tendencies and rarely a patient may present with thrombosis. One explanation that has been advanced for this phenomenon is the possibility of existence of modifier gene/alleles, which may have a role in decreasing the severity of bleeding (1).
In conclusion, we have described a case of $\mathrm{CA}$, a very rare bleeding disorder, in a black Kenyan child. Although CA is not a publichealth problem in Kenya, it is nevertheless important to recognise the condition because appropriate management leads considerable improvement in the patient's quality of life, and may also be life saving. In our patient, gynaecologic and obstetric challenges are anticipated. These challenges can be managed appropriately and in addition the patient and the parents will be mentally prepared for them.

\section{ACKNOWLEDGEMENTS}

To Dr. A. Riddell, the Chief of The Royal Free Hospital Haemophilia and Thrombosis Unit, for assistance in the assay of fibrinogen assay, and for cross-checking our other coagulation tests.

\section{REFERENCES}

1. Consultative Hemostasis and Thrombosis. Kitchens S.C., Alving B.M, Kessler C.M. 2nd Edition, 2007, Saundres Elsevier, Philadelphia, PA, USA.

2. International Registry of Rare Bleeding Disorders website: www.rbdd.org Last accessed on 29th November 2009.

3. Menache, D. Congenital fibrinogen abnormalities. Ann. NY. Acad. Sci. 1983; 408: 121- 1230.

4. Peyvandi, F., Cattaneo,A.D.E.,Moerloose, P. etal. Rare bleeding disorders. Haemophilia. 2008; 14 (Supp.3): 202-210.

5. Congenital Disorders of Fibrinogen. Shannon L., Meeks M.D. In:Transfusion Medicine and Hemostasis, $1^{\text {st }}$ Edition, Elservier, 2009, London, California, New York.

6. Acharya, S. S. and Dimicelle, D. M., Rare inherited disorders of fibrinogen. Hemophilia. 2008; 14: 11511158. 